\title{
INTERPRETIVE SUMMARIES, NOVEMBER 2013
}

Effect of $\beta$-lactoglobulin A and B whey protein variants on cheese yield potential of a model milk system. By Meza-Nieto et al., page 677\%. This study demonstrated that the addition of $\beta$-lactoglobulin $(\beta-\mathrm{LG})$ whey protein genetic variants $\mathrm{A}$ or $\mathrm{B}$ to a model milk system determines its cheese yield potential beyond what can be explained by their association with milk composition. Capillary electrophoresis showed that higher cheese yield for $\beta$-LG $B$ than for $\beta$-LG A was due to greater retention of $\beta$-LG B in the miniature cheese model. Furthermore, addition of whey protein increased cheese yield up to a maximun level, after which it drastically decreased. This knowledge is expected to be useful in maximizing cheese yield and optimizing processing conditions during manufacture of cheese and cheese analogs.

http://dx.doi.org/10.3168/jds.2012-5961.

Crystallization mechanisms in cream during ripening and initial butter churning. By Buldo et al., page 6782. The temperature treatment of cream is the time-consuming step in butter production. A better understanding of the mechanisms leading to milk fat crystallization during ripening and churning of the cream will contribute to optimization of the production process. We studied the effect of different ripening times on change in viscosity, level of solid fat content, particle size distribution, crystal polymorphism, and thermal behavior of the cream during ripening and churning. The crystallization state that promotes partial coalescence (i.e., aggregation of butter grains) is obtained within the first hour of cream ripening at $10^{\circ} \mathrm{C}$.

http://dx.doi.org/10.3168/jds.2012-6066.

Preliminary selection for potential probiotic $B i$ fidobacterium isolated from subjects of different Chinese ethnic groups and evaluation of their fermentation and storage characteristics in bovine milk. By Liu et al., page 680\%. Individual ethnic minority groups in China are characterized by having distinct physical and cultural traits, including lifestyles, customs, eating habits, and diets. These differences may contribute to the creation of a rich and distinctive spectrum of intestinal microflora. Therefore, it would be of great scientific interest to identify and to screen for potential probiotic Bifidobacterium species in these ethnic populations. Twenty-nine strains of Bifidobacterium were obtained from 18 samples of human feces collected from different ethnic minority regions of China. Four out of 29 strains were preliminarily selected by in vitro tests. In addition, the fermentation efficiency and the storage characteristics of these strains in fermented bovine milk were evaluated.

http://dx.doi.org/10.3168/jds.2013-6582.
Minimizing photooxidation in pasteurized milk by optimizing light transmission properties of green polyethylene films. By Intawiwat et al., page 6818. New custom-made green polyethylene films with different light transmission were used to investigate the abilities to protect against photooxidation in pasteurized milk at different exposure times. Samples covered with green films had significantly less sunlight and rancid flavors than those covered with orange and transparent films. The green film that blocked wavelengths below $450 \mathrm{~nm}$ and reduced light transmission below $5 \%$ for the wavelengths above $600 \mathrm{~nm}$ provided the best protection against sensory deterioration and degradation of photosensitizer in milk.

http://dx.doi.org/10.3168/jds.2013-6584.

Effect of increasing the protein-to-fat ratio and reducing fat content on the chemical and physical properties of processed cheese product. $B y$ Guinee and O'Callaghan, page 6830. Reducing the fat content of processed cheese product (PCP) incrementally from 33 to $14 \mathrm{~g} / 100 \mathrm{~g}$, while maintaining a constant moisture content, significantly increased the firmness and decreased the meltability and fluidity of the heated PCP. These changes coincided with increases in total protein content and reductions in the proportions of total protein and total calcium that were water soluble. http://dx.doi.org/10.3168/jds.2013-6685.

Effect of different feeding strategies in intensive dairy farming systems on milk fatty acid profiles, and implications on feeding costs in Italy. By Borreani et al., page 6840. We studied feeding strategies for intensive dairy farming systems, based on corn silage having different protein supplement: off-farm concentrate, home-grown grass silage, or fresh herbage. The off-farm concentrate-based systems had the greatest milk production per hectare but also the greatest feeding costs. The use of home-grown forages reduced feeding costs, making these feeding systems economically competitive, even for a lower milk yield per cow. The studied systems highlighted a variety of milk fatty acid profiles. The milk of home-grown forage-based systems had a fatty acid profile more like that recommended for human nutrition, especially considering the $\Sigma$ n-6: $\Sigma$ n-3 ratio.

http://dx.doi.org/10.3168/jds.2013-6710.

Effects of seasonal change and parity on raw milk composition and related indices in Chinese Holstein cows in northern China. By Yang et al., page 6863. Raw milk composition not only reflects the dairy quality and health status of dairy cows, but also affects the nutritional value of milk and dairy products. 
The effects of seasonal change and parity on milk composition and related indices were investigated in this study. The production, components, and sanitary state of milk were influenced in the hot season, and more attention should be paid to dairy cows at high parity. We found some correlations among these indices. This study also developed new models to quantify the effects of seasonal change on milk composition

http://dx.doi.org/10.3168/jds.2013-6846.

Mastitis control in Swedish dairy herds. By Nielsen and Emanuelson, page 6883. The aim was to investigate which preventive measures targeting mastitis are implemented in Swedish dairy herds having different housing and milking systems. Freestall herds with milking parlors implemented more measures related to milking hygiene and routines. In freestall herds, lactating cows were seldom grouped according to udder health. Dry cows were rarely grouped according to udder health, and the majority of freestall herds did not implement a milking order. These findings can be used to target advice and thereby improve the efficiency of mastitis control and udder health in cows.

http://dx.doi.org/10.3168/jds.2012-6026.

Dairy producer attitudes to pain in cattle in relation to disbudding calves. By Wikman et al., page 6894. Pain is an important indicator of poor animal welfare. Producer attitudes towards pain and animal welfare influence livestock management. Using a questionnaire, our aim was to quantify attitudes of Finnish dairy producers to the painfulness of various cattle diseases and management practices. Attitudes towards disbudding and cattle pain were measured. Four factors were identified: "taking disbudding pain seriously", "sensitivity to pain caused by cattle diseases", "ready to medicate calves myself", and "pro horns". Compared with men, women rated pain higher and were more positive towards pain medication for animals. Maintaining horns is more important for producers with tiestalls than for producers with freestalls.

http://dx.doi.org/10.3168/jds.2012-6128.

Timed artificial insemination programs during summer in lactating dairy cows: Comparison of the 5-d Cosynch protocol with an estrogen/ progesterone-based protocol. By Pereira et al., page 6904. Timed artificial insemination (TAI) programs generally synchronize emergence of a new ovarian follicular wave and induce a synchronized ovulation either with analogs of gonadotropin-releasing hormone $(\mathrm{GnRH})$ or with estradiol $\left(\mathrm{E}_{2}\right) 17 \beta$. Previous studies have not directly compared GnRH-based with $\mathrm{E}_{2} /$ progesterone $\left(\mathrm{P}_{4}\right)$-based protocols that are designed to have short periods from follicular emergence until ovulation in synchronized cows. The 5-d Cosynch protocol resulted in a greater percentage of cows that had their estrous cycle synchronized compared with the $\mathrm{E}_{2} / \mathrm{P}_{4}$ protocol; however, the $\mathrm{E}_{2} / \mathrm{P}_{4}$ protocol increased pregnancy success to TAI primarily because of a reduction in pregnancy loss from 32 to $60 \mathrm{~d}$. Therefore, increased $\mathrm{E}_{2}$ concentrations near the time of AI might positively affect pregnancy success and pregnancy maintenance in lactating dairy cows.

http://dx.doi.org/10.3168/jds.2012-6260.

The effect of internal teat sealant products (Teatseal and Orbeseal) on intramammary infection, clinical mastitis, and somatic cell counts in lactating dairy cows: A meta-analysis. $B y$ Rabiee and Lean, page 6915. This meta-analysis of effects of internal teat sealants (Teatseal and Orbeseal) in dairy cattle found that these treatments significantly reduced the incidence of intramammary infection and clinical mastitis whether studies were conducted with a negative control or in conjunction with antibiotic treatment in both groups. Variability in all responses was evident, and sources of variation were explored by meta-regression, but no significant influences on responses to treatment were identified.

http://dx.doi.org/10.3168/jds.2013-6544.

Short-term effects of dietary trans fatty acids compared with saturated fatty acids, on selected measures of inflammation, fatty acid profiles, and production in early lactating Holstein dairy cows. By Watts et al., page 6932. Dietary fat has the potential to modulate immune function during the critical postpartum period in cows. Holstein cows were fed diets containing supplemental fats, including trans fats, starting $1 \mathrm{wk}$ postpartum, and changes in blood lipids and gene expression of immune cells were examined. Expression of genes associated with increased inflammation were greater in cows fed diets supplemented with saturated fat compared with trans fat, but the changes in gene expression were not associated with changes in systemic inflammation. Feeding supplemental saturated fat or trans fat could alter the function of immune cells during the critical postpartum period. http://dx.doi.org/10.3168/jds.2012-6430.

Hepatic and extrahepatic expression of serum amyloid A3 during lactation in dairy cows. By Saremi et al., page 6944. Serum amyloid A (SAA) is one of the major acute-phase proteins; the SAA3 isoform is produced mainly in extrahepatic tissues in response to local inflammation. We herein demonstrated that SAA3 is a bovine adipokine and that adipose tissue, besides the mammary gland, might be an important source of SAA3. The highest mRNA abundance of SAA3 was observed around parturition in all tissues studied. http://dx.doi.org/10.3168/jds.2012-6495. 
Detection and enumeration of Staphylococcus aureus by real-time polymerase chain reaction. By Botaro et al., page 6955. Because Staphylococcus aureus still challenges intramammary infection diagnosis worldwide, we aimed to develop a rapid, highly sensitive molecular method (quantitative polymerase chain reaction, $\mathrm{qPCR}$ ) to detect this pathogen in milk from infected mammary glands. Furthermore, based on ability of qPCR to quantify genes, the enumeration of the pathogen and somatic cells in milk was proposed. The detection limit of the qPCR protocol of inoculated Staph. aureus in bronopol-preserved milk samples was $1.04 \times 10^{1} \mathrm{cfu} / \mathrm{mL}$. However, the proposed qPCR protocol was not accurate for counting Staph. aureus from naturally infected mammary glands.

http://dx.doi.org/10.3168/jds.2013-6559.

Testing Rhodiola sachalinensis saccharide as cryoprotectant for bovine spermatozoa. By Cao et al., page 6965. Rhodiola sachalinensis saccharide (RSS) conferred a great cryoprotective capacity to the basic extender for bull spermatozoa. Sperm motility, mitochondrial activity, and membrane and acrosome integrity were improved during the freezing-thawing process. Activities of specific enzymes in bull cryopreserved sperms, such as superoxide dismutase, lactate dehydrogenase, and glutamic-oxalacetic transaminease showed increases in the extender with RSS. The optimal concentration of RSS in basic extender was 0.06 $\mathrm{mg} / \mathrm{mL}$.

http://dx.doi.org/10.3168/jds.2013-6623.

Effect of milking frequency on the behavior and productivity of lactating dairy cows. By Hart et al., page 6973. The objective of this study was to determine the effect of milking frequency on the behavioral patterns and productivity of lactating dairy cows. Compared with milking twice per day, milking 3 times per day $(3 \times / \mathrm{d})$ increased production and altered the distribution of feeding activity throughout the day. Multiparous cows consumed longer and slightly larger meals when milked $3 \times /$ d. Alternatively, primiparous cows consumed smaller, more frequent meals throughout the day when milked 3 times per day. Thus, milking $3 \times / d$ can be used to increase production; however, greater milking frequency elicits varying effects on the behavior of primiparous and multiparous cows, suggesting that grouping and management of cows based on parity may be beneficial.

http://dx.doi.org/10.3168/jds.2013-6764.

Subclinical hypocalcemia, plasma biochemical parameters, lipid metabolism, postpartum disease, and fertility in postparturient dairy cows. By Chamberlin et al., page 7001. The objective of this study was to evaluate blood calcium concentrations at calving, plasma biochemical parameters, lipid metabo- lism, postpartum disease occurrence, milk production, and fertility in postparturient multiparous Holstein cows. Approximately $50 \%$ of mature dairy cows may experience hypocalcemia at calving, and hypocalcemia has been linked to postparturient diseases and disorders that cost the dairy industry billions of dollars each year. The results of this study indicate an association between subclinical hypocalcemia at calving, plasma biochemical changes, lipid metabolism, and fatty liver in multiparous Holstein dairy cows.

http://dx.doi.org/10.3168/jds.2013-6901.

Environmental efficiency of alternative dairy systems: A productive efficiency approach. By Toma et al., page 7014. This work evaluates the environmental efficiency of divergent dairy management styles by quantifying the relationships between undesirable outputs (i.e., pollution) and desirable outputs and inputs over time. The analysis considered nitrogen and phosphate surpluses as well as greenhouse gas emissions alongside the "traditional" inputs and outputs in a productive efficiency approach. Data envelopment analysis models were applied and results indicated significant differences between environmental efficiency scores between dairy systems (mainly due to genetic rather than feed system differences), but no significant changes between years. Additionally, animal health has a significant effect on environmental efficiency of each dairy system.

http://dx.doi.org/10.3168/jds.2013-6911.

Supplemental progesterone and timing of resynchronization on pregnancy outcomes in lactating dairy cows. By Bilby et al., page 7032. Resynchronization strategies continue to be a challenge because of poor fertility compared with first artificial insemination (AI). Use of a supplemental progesterone with a controlled internal drug-releasing (CIDR) insert improved pregnancies per $\mathrm{AI}(\mathrm{P} / \mathrm{AI})$ when resynchronization was initiated $39 \mathrm{~d}$ but not $32 \mathrm{~d}$ after the pre-enrollment AI. In addition, CIDR treatment increased P/AI when cows had no corpus luteum or when progesterone was $<1 \mathrm{ng} / \mathrm{mL}$ at the first gonadotropin-releasing hormone injection of the resynchronization protocol. Incorporating supplemental progesterone during resynchronization for timed AI improved fertility of cows not in diestrus. http://dx.doi.org/10.3168/jds.2013-6960.

Applying additive logistic regression to data derived from sensors monitoring behavioral and physiological characteristics of dairy cows to detect lameness. By Kamphuis et al., page 7043. Lameness negatively affects cow welfare and decreases farm profitability. Detecting lame cows visually is difficult and becomes more challenging as herd size increases. Automated detection of lame cows may be a viable aid or alternative to visual detection. The hypothesis was 
that data derived from sensors monitoring behavioral and physiological characteristics of dairy cows are useful to automate the detection of lameness. Univariable and multivariable models were developed using a data-mining technique. The multivariable model outperformed the univariate models but detection performance was still not sufficiently high to warrant implementation in practice on large, pasture-based dairy farms.

http://dx.doi.org/10.3168/jds.2013-6993.

Short communication: Herd-level reproductive performance and its relationship with lameness and leg injuries in freestall dairy herds in the northeastern United States. By Chapinal et al., page 7066. Herd-level reproductive outcomes and the prevalence of lameness and hock and knee injuries were assessed in multiparous cows in 53 freestall herds in the northeastern United States. Herds with higher prevalence of lameness had longer average calving to conception interval and calving interval. Management to reduce rates of lameness may improve reproductive performance at the herd level.

http://dx.doi.org/10.3168/jds.2013-6967.

Short communication: Lymphoproliferative response to lipopolysaccharide and incidence of infections in periparturient dairy cows. By Catalani et al., page 707\%. Immune response traits may help to predict the risk of infections in periparturient dairy cows. Single nucleotide polymorphisms located in the toll-like receptor $4(T L R-4)$ gene can partly account for differences in resistance to bacterial infections.

http://dx.doi.org/10.3168/jds.2013-6854.

Short communication: Antimicrobial efficacy of intramammary treatment with a novel biphenomycin compound against Staphylococcus aureus, Streptococcus uberis, and Escherichia coli-induced mouse mastitis. By Demon et al., page 7082. Antimicrobial therapy is a principal tool to control bovine mastitis. Despite intensive research, the major bovine mastitis-inducing pathogens Staphylococcus aureus, Streptococcus uberis, and Escherichia coli cannot yet be eradicated. Hence, novel antimicrobial therapies remain highly desired. The current in vivo mouse study showed adequate antimicrobial efficacy of the novel biphenomycin compound AIC102827 against these bovine pathogens.

http://dx.doi.org/10.3168/jds.2013-7011.

Short communication: Rumination and feeding behavior before and after calving in dairy cows. By Schirmann et al., page 7088. The aims of this study were to describe changes in rumination and feeding behavior around calving. Eleven freestall-housed cows were monitored from $96 \mathrm{~h}$ before to $48 \mathrm{~h}$ after calving for rumination time, feeding time, and dry matter intake. Cows spent less time ruminating and feeding in the $24 \mathrm{~h}$ before calving, and these 2 behaviors continued to decline for an additional $24 \mathrm{~h}$ after calving. Changes in time spent ruminating and feeding show promise as tools to identify cows that will soon calve. http://dx.doi.org/10.3168/jds.2013-7023.

Dietary starch source and protein degradability in diets containing sucrose: Effects on ruminal measures and proposed mechanism for degradable protein effects. By Hall, page 7093. Microbes in the rumen digest feed for the cow and supply her with nutrients, including organic acids. Most organic acids come from fermentation of carbohydrates. However, in cows fed diets with more rather than less degradable protein, greater amounts of organic acids and lactate were in the rumen, independent of carbohydrate source. Protein supply changed the products formed from carbohydrate. Learning more about how to manipulate products formed by rumen microbes will enable us to formulate diets to increase or predict nutrient output from the rumen to more efficiently meet the nutrient requirements of the cow.

http://dx.doi.org/10.3168/jds.2012-5663.

Nutritive value, fermentation characteristics, and in situ disappearance kinetics of sorghum silage treated with inoculants. By Thomas et al., page 7120. The use of sorghum silage as cattle feed or biofuel feedstock is hindered by storage constraints and fiber degradation, both of which may be improved by treating the silage with fibrolytic enzymes or microbial inoculants. Little research has been done on the treatment of sorghum silage with fibrolytic enzymes or microbial inoculants. Published results will benefit sorghum producers, dairy producers, cattle feeders, and lignocellulosic biofuel processors. Producers of sorghum for biofuels and processors of feedstock will benefit from information that may improve the storage longevity of sorghum silage and simultaneously decentralize pretreatment of sorghum silage for ethanol production. Fibrolytic enzyme and microbial inoculants are both recommended to improve fiber degradation; however, only fibrolytic enzyme inoculant is recommended to improve ensiling characteristics.

http://dx.doi.org/10.3168/jds.2013-6635.

Effects of intrajugular glucose infusion on feed intake, milk yield, and metabolic responses of early postpartum cows fed diets varying in protein and starch concentration. By Brown and Allen, page 7132. Feed intake in transition dairy cows is commonly suppressed by a complex set of metabolic factors. Increasing feed intake during this period is an important strategy to minimize costly postpartum metabolic diseases. This study examines mechanisms whereby feed intake may be depressed in early postpar- 
tum cows, and assists in developing feeding strategies involving varying starch and protein concentrations to improve feed intake. Diets varying in starch and protein concentration resulted in changes in metabolism and milk production performance, which can interact to suppress feed intake.

http://dx.doi.org/10.3168/jds.2013-6636.

Palmitic acid increased yields of milk and milk fat and nutrient digestibility across production level of lactating cows. By Piantoni et al., page 7143. In dairy cows, responses to highly saturated fats have varied greatly across experiments. Therefore, it is currently not clear when or if such supplements should be fed. Nearly all fat supplements available are a mix of fatty acids, and the effects of specific fatty acids on production differ. This experiment was designed to evaluate the effects of palmitic acid on cows varying in milk yield to identify benefits of fat supplementation to lactating cows. Palmitic acid has the potential to increase yields of milk and milk fat, independent of production level, without increasing body condition score or body weight.

http://dx.doi.org/10.3168/jds.2013-6680.

Plane of nutrition during the preweaning period but not the grower phase influences the neutrophil activity of Holstein calves. By Obeidat et al., page 7155. Dairy calves are susceptible to morbidity and mortality. Improving leukocyte responses may improve disease resistance. Therefore, the effects of plane of nutrition during preweaning and grower periods on performance and leukocyte responses of dairy calves were evaluated. Holstein calves fed a high plane of nutrition had greater average daily gain and were more efficient than calves fed a low plane of nutrition. Neutrophil responses were greater in calves fed a low plane of nutrition compared with calves fed a high plane of nutrition during the preweaning period; however, this effect was not observed during the immediate postweaning or grower periods.

http://dx.doi.org/10.3168/jds.2013-6699.

Milk volatile organic compounds and fatty acid profile in cows fed timothy as hay, pasture, or silage. By Villeneuve et al., page 7181. Cows were fed timothy as hay, pasture, or silage to determine the effect of forage type on milk organoleptic characteristics. The ratio of palmitic to oleic acids in milk fat, which influences its melting properties, was lower for cows on pasture. The forage type affected free fatty acids, aldehydes, alcohols, sulfur compounds, ketones, lactones, terpenes, and phenolic compounds in milk. No flavor difference was detected between milk from cows fed hay or silage but there was a difference between milk from cows fed hay or pasture. The taste of milk was affected by the type of forage fed to cows.

http://dx.doi.org/10.3168/jds.2013-6785.

Unique interrelationships between fiber composition, water-soluble carbohydrates, and in vitro gas production for fall-grown oat forages. By Coblentz et al., page 7195. Fall-grown oat forages that undergo winter-hardening during the late-elongation or early-boot stages of growth can exhibit abnormally high concentrations of water-soluble carbohydrates. This creates an unusual paradigm where forage maturity is positively related to energy density. The results of these studies evaluating in vitro gas production indicate that fall-grown oat possesses unique nutritional characteristics, many of which are associated with high concentrations of water-soluble carbohydrates. Production trials with lactating cows or dairy replacement heifers are needed to determine how to best use these unique, but naturally occurring, sugar pools found within fall-grown oat forages.

http://dx.doi.org/10.3168/jds.2013-6889.

Evaluation of rumen-protected lysine supplementation to lactating dairy cows consuming increasing amounts of distillers dried grains with solubles. By Paz et al., page 7210. Diets with increasing amounts of distillers dried grains with solubles were supplemented with rumen-protected lysine (Lys) to evaluate the effects on milk yield, milk composition, and plasma amino acids. Plasma Lys decreased as distillers dried grains with solubles increased up to $20 \%$ of the diet dry matter but milk and fat yields were maintained and protein was increased. Greater intake and lower milk yield than anticipated resulted in diets that were predicted to meet Lys requirements; thus, supplementation with rumen-protected Lys was not beneficial and had no effects on plasma concentration of other amino acids, which supported that Lys was not limiting.

http://dx.doi.org/10.3168/jds.2013-6906.

Repeated mixing and isolation: Measuring chronic, intermittent stress in Holstein calves. By Wilcox et al., page 7223. Stress is frequently confirmed in mice by a glucose consumption test. We tested whether chronic stress could be induced in neonatal calves and whether molasses consumption would increase with that stress. Calves that were stressed by isolation and regrouping increased molasses consumption and showed increases in the stress hormone cortisol, but could not respond to a challenge to produce cortisol (indicating chronic stress). Behaviors such as latency to lie and time spent standing were also greater for the stressed calves. Our results confirm that chronic 
stress could be achieved with repeated isolation and mixing and that molasses consumption was enhanced by that stressor.

http://dx.doi.org/10.3168/jds.2013-6944.

Hyperkalemia in neonatal diarrheic calves depends on the degree of dehydration and the cause of the metabolic acidosis but does not require the presence of acidemia. By Trefz et al., page 7234. Hyperkalemia in neonatal calves with diarrhea was traditionally attributed to acidemia with impaired intracellular translocation of potassium ions as the proposed underlying mechanism. We identified risk factors in a large study population of neonatal diarrheic calves and found that hyperkalemia is an inconsistent finding in acidemic calves. Strongest associations were identified between plasma potassium concentrations and indices of dehydration and renal function, which also had a major effect on acid-base derangement in hyperkalemic calves. The results of this study provide an improved understanding of the pathophysiology of hyperkalemia and emphasize the importance of rehydration in the treatment of diarrheic calves.

http://dx.doi.org/10.3168/jds.2013-6945.

Factors affecting energy and nitrogen efficiency of dairy cows: A meta-analysis. By Phuong et al., page 7245. Improvement of feed efficiency is important for a dairy farm in terms of profitability and environmental impact, but efficiency of utilizations of both energy and nitrogen should be considered. This study found a strong correlation between energy and nitrogen efficiency. Acid detergent fiber, proportion of concentrate, and digestible energy were the common nutritional factors affecting feed efficiency.

http://dx.doi.org/10.3168/jds.2013-6977.

Effect of feed presentation on feeding patterns of dairy calves. By Miller-Cushon et al., page 7260. This study examined how exposure to different feed presentations (hay and concentrate provided as separate components or as a mixture) affects feeding patterns of dairy calves around weaning. Calves provided a mixed ration spent more time feeding at a lower rate of intake than calves provided separate components. Provision of the mixed ration also resulted in more evenly distributed diurnal feeding patterns. Feeding patterns were similar once all calves were fed the mixed ration. These results indicate that feed presentation affects feeding behavior of dairy calves around weaning, but does not influence development of longer-term feeding patterns. http://dx.doi.org/10.3168/jds.2013-7013.

Genetic analyses of claw health in Norwegian Red cows. By Ødegård et al., page 7274. Claw health is important both from an economical point of view and for animal welfare reasons. In Norway, claw health data has been recorded since 2004; normal (healthy) claws and 9 defined claw disorders are recorded at claw trimming. Records from 141,659 Norwegian Red cows were analyzed. Claw disorders were analyzed as single traits and as grouped traits. Heritability ranged from 0.04 (lameness and acute trauma) to 0.23 (corkscrew claw). Claw disorders are heritable and could be included in a breeding scheme.

http://dx.doi.org/10.3168/jds.2012-6509.

Estimates of genetic parameters and eigenvector indices for milk production of Holstein cows. By Savegnago et al., page 7284. Random regression models were used to estimate the genetic parameters for monthly test-day milk yield. The genetic gains for milk yield and persistency were compared using selection indices based on eigenvectors and selection indices that did not use eigenvectors. If the breeding goals were milk production and persistency, the complete sequential eigenvector index with higher economic values for persistency was indicated. If the breeding goal was to improve only milk yield, the traditional selection index was found to be more desirable.

http://dx.doi.org/10.3168/jds.2013-6708.

A first step toward genomic selection in the multi-breed French dairy goat population. By Carillier et al., page 7294. Use of molecular information has improved the accuracy of the genetic breeding values of young males in species such as dairy cattle and sheep. The recent availability of molecular techniques in dairy goats led us to study the population structure and the effect of molecular data on the accuracy of predicted breeding values. This study focused on the effect of adding molecular data from males and from less informative females into genetic evaluations. The results, obtained using the genomic best linear unbiased predictor (BLUP) model, were not as good as those in other species.

http://dx.doi.org/10.3168/jds.2013-6789.

Unraveling the genetic architecture of environmental variance of somatic cell score using highdensity single nucleotide polymorphisms and cow data from experimental farms. By Mulder et al., page 7306. Cows differ not only in their mean for a trait within a lactation period but also in the variation around that mean. Using somatic cell score data of cows at experimental farms, we found that variation around the mean is heritable and affected by many genes. The method developed in this study improves accuracy of breeding values when single nucleotide polymorphism information is available and can therefore help in improving mastitis resistance by selection. http://dx.doi.org/10.3168/jds.2013-6818. 
Genome-wide association analysis to identify genotype $\times$ environment interaction for milk protein yield and level of somatic cell score as environmental descriptor in German Holsteins. By Streit et al., page 7318. Genotype $\times$ environment interactions are frequently studied in dairy cattle breeding using reaction norm models. Often the environment is modelled by average herd milk production levels, but the level of udder health and hygiene might also be an important environmental factor. In this article, we report the results from a large-scale genome-wide association analysis for the intercept and slope of milk protein reaction norms when using the average herd-test-day solution for somatic cell score as an environmental descriptor. We were able to detect and confirm several single nucleotide polymorphism clusters affecting intercept and slope. The results may have implications for breeding robust cows.

http://dx.doi.org/10.3168/jds.2013-7133.

Short communication: Genetic analysis of dairy bull fertility from field data of Brown Swiss cattle. By Tiezzi et al., page 7325. This study investigated the effect of artificial insemination service bull on calving per service and nonreturn rate at 56 days after service. A threshold animal model was used to estimate variance components for the aforementioned traits. Additive genetic variation and repeatability for semen fertility were very low, and thus genetic improvement for service bull fertility using field data does not seem feasible.

http://dx.doi.org/10.3168/jds.2013-6885.

Assessing the research and education needs of the organic dairy industry in the northeastern United States. By Pereira et al., page 7340. The goal of this study was to develop an initial understanding of the emerging research and educational needs of organic dairy stakeholders from the northeastern United States. Focus group interviews were conducted followed by a survey questionnaire that identified the following topics as high priorities for organic dairy farmers: direct marketing, estimating pasture intake, and animal health. Future outreach efforts, focused on these areas of need, will provide the greatest benefit to the organic dairy industry in general, and to northeastern organic dairy farmers in particular.

http://dx.doi.org/10.3168/jds.2013-6690.
Identifying efficient dairy heifer producers using production costs and data envelopment analysis. By Heinrichs et al., page 7355. The cost to raise heifers has significantly increased in the past 10 yr, and averaged $\$ 1,808$ from birth to calving, with feed representing $73 \%$ of total costs in this study. Data envelopment analysis determined that efficient farms spent, on average, $\$ 1,137.40$ and $\$ 140.62 /$ heifer for feed and labor, respectively, on heifers that calved at 23.7 mo of age and produced $88.42 \%$ of the milk produced by older cows. The heifer enterprise is the second- or third-largest contributor to the total cost of producing milk, and this study provides information that can help dairy farms improve their competitive position now and in the future.

http://dx.doi.org/10.3168/jds.2012-6488.

Whole-milk feeding duration, calf growth, and profitability of group-fed calves in an organic production system. By Bjorklund et al., page 7363. The objective of the study was to evaluate the effect of early-life feeding duration on growth and economics of organic dairy calves fed once per day. Early-weaned calves had lower body weight than later-weaned calves; however, weaning groups did not differ for body weight at 120 days of age. Total costs and cost per kilogram of gain for the first 90 days were lowest for early-weaned calves. Some heifer calves fed whole milk in a groupfed organic production system achieved adequate gains during the pre- and postweaning periods. http://dx.doi.org/10.3168/jds.2013-6772.

Variation in nutrients formulated and nutrients supplied on $\mathbf{5}$ California dairies. By Rossow and Aly, page 7371. Deviations in nutrients due to feed management affect milk production and are not accounted for in current ration formulation models. Based on feeding and milk production data collected on 5 California dairies, correlations of variability in nutrients and variability in milk production were analyzed to identify an index to represent feed management in ration formulation.

http://dx.doi.org/10.3168/jds.2013-7084. 